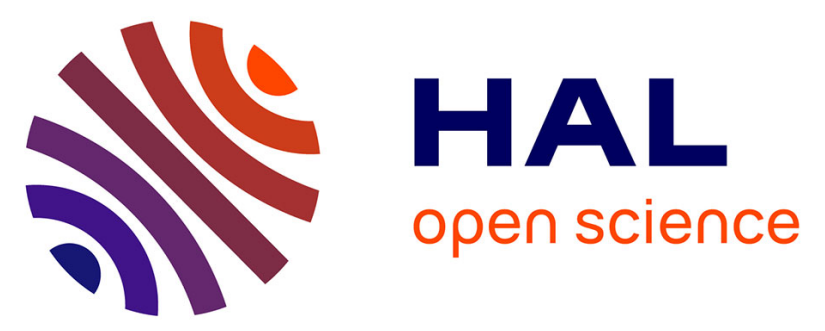

\title{
Deposition and dielectric study as function of thickness of perovskite oxynitride SrTaO2N thin films elaborated by reactive sputtering
}

Florent Marlec, Claire Le Paven, Laurent Le Gendre, Ratiba Benzerga, François Cheviré, Franck Tessier, F Gam, Ala Sharaiha

\section{To cite this version:}

Florent Marlec, Claire Le Paven, Laurent Le Gendre, Ratiba Benzerga, François Cheviré, et al.. Deposition and dielectric study as function of thickness of perovskite oxynitride $\mathrm{SrTaO} 2 \mathrm{~N}$ thin films elaborated by reactive sputtering. Surface and Coatings Technology, 2017, 324, pp.607-613. 10.1016/j.surfcoat.2016.10.053 . hal-01392710

\author{
HAL Id: hal-01392710 \\ https://hal.science/hal-01392710
}

Submitted on 8 Nov 2016

HAL is a multi-disciplinary open access archive for the deposit and dissemination of scientific research documents, whether they are published or not. The documents may come from teaching and research institutions in France or abroad, or from public or private research centers.
L'archive ouverte pluridisciplinaire HAL, est destinée au dépôt et à la diffusion de documents scientifiques de niveau recherche, publiés ou non, émanant des établissements d'enseignement et de recherche français ou étrangers, des laboratoires publics ou privés. 


\title{
Deposition and dielectric study as function of thickness of perovskite oxynitride $\mathrm{SrTaO}_{2} \mathrm{~N}$ thin films elaborated by reactive sputtering
}

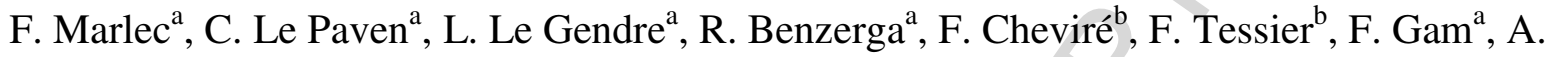 \\ Sharaiha $^{\mathrm{a}}$
}

${ }^{a}$ Institut d'Electronique et de Télécommunications de Rennes (IETR), Equipe Matériaux Fonctionnels, IUT Saint-Brieuc, Université de Rennes 1, 22000 Saint Brieuc, France.

\footnotetext{
${ }^{\mathrm{b}}$ Institut des Sciences Chimiques de Rennes (ISCR - UMR CNRS 6226), Equipe Verres et Céramiques, Université de Rennes 1, 35042 Rennes cedex, France.
}

\begin{abstract}
The present study concerns the deposition of perovskite oxynitride $\mathrm{SrTaO}_{2} \mathrm{~N}$ films and their dielectric characterization at low frequencies. Those radio frequency sputtered thin films have been obtained under a reactive plasma (92.3 vol.\% Ar / 7.7 vol. $\left.\% \mathrm{~N}_{2}\right)$ for substrate temperatures ranging from 600 to $900^{\circ} \mathrm{C}$. As shown by X-rays diffraction and band-gap measurements, the deposition temperature $\left(T_{S}\right)$ determines the film structure and leads to films with band-gap and cell volume approaching the ones of the $\mathrm{SrTaO}_{2} \mathrm{~N}$ bulk material with increased $\mathrm{T}_{\mathrm{S}}$. The dielectric study has been performed on polycrystalline, textured and epitaxial $\mathrm{SrTaO}_{2} \mathrm{~N}$ layers deposited on conductive niobium doped $\mathrm{SrTiO}_{3}$ substrates and thickness of films ranging from 30 to $900 \mathrm{~nm}$. The related permittivities vary from 66.5 to 90 (@10kHz, room temperature). These low values do not point out an effect of the crystallographic strain of films, due to their thickness, on the permittivity values. The latter
\end{abstract}


remains irrespective of the frequency up to $100 \mathrm{kHz}$ and does not vary upon the application of an external DC voltage.

\section{Keywords}

Oxynitride; Perovskite; Thin films; Reactive Sputtering; Epitaxy; Permittivity

\section{Highlights}

- Perovskite oxynitride $\mathrm{SrTaO}_{2} \mathrm{~N}$ films were deposited by reactive sputtering

- Polycrystalline, textured and epitaxial films were obtained

- Band gap and cell volume approach those of bulk with increasing substrate temperature

- No influence of a moderate crystallographic strain on the permittivity has been evidenced

- Permittivity of films with different thicknesses varies from 66.5 to 90 at $10 \mathrm{kHz}$ 


\section{Introduction}

The family of perovskite compounds contains numerous dielectric and ferroelectric materials suitable for integration in electronic and telecommunication devices. The wide variety of their compositions is the result of a broad range of cationic substitutions. In this way, the modulation of the formulation helps to adjust the electronic properties of the material, as for example for the ferroelectric $\mathrm{Ba}_{1-\mathrm{x}} \mathrm{Sr}_{\mathrm{x}} \mathrm{TiO}_{3}$ (BST) having a Curie temperature shifting with the $\mathrm{Ba} / \mathrm{Sr}$ ratio [1]. Perovskite oxynitride materials are obtained by crosssubstitution of cations and anions [2], with the requirement of the electroneutrality of the compound. Several reports have underlined the original properties of the perovskite oxynitrides compared to their parent oxides. In particular, the $\mathrm{AMO}_{2} \mathrm{~N}$ materials (with $\mathrm{M}=$ $\mathrm{Ti}, \mathrm{Nb}, \mathrm{Ta}$ and $\mathrm{A}=$ lanthanide, alkaline or alkaline earth ions) present an absorption in the visible region, with potential use as pigment $[3,4]$ or/and photocatalyst, for example in visible overall water splitting [5]. The anionic substitution also influences the electrical properties of the resulting structures. Some reports have emphasized high permittivity values of several thousands for this class of materials [6-8], as well as local ferroelectric behaviors $[9,10]$. To address these unusual properties, different structural models, based on a nitride anion ordering, have been proposed. Crystal structure refinement and first-principles calculations show that the stable cis-configuration of the nitrogen atoms in the $\mathrm{MO}_{4} \mathrm{~N}_{2}$ octahedra $[11,12]$ gives rise to a large tilting of the latter $[13,14]$ inducing permanent polarizations and high permittivities. An alternative trans-type model has been recently exposed by Oka et al. on $\mathrm{SrTaO}_{2} \mathrm{~N}$ thin films deposited by nitrogen-plasma-assisted laser ablation [9]. The alignment of the $\mathrm{N}$ atoms along the c-axis of films was assumed to be stabilized by the epitaxial growth of samples. The latter also gave rise to a tetragonal distortion of the perovskite cells, with high $c / a$ ratios, as for example $c / a=1.013$ for a $290 \mathrm{~nm}$ thick $\mathrm{SrTaO}_{2} \mathrm{~N}$ film (with $c$, the out-ofplane axis parameter, and $a$, the in-plane axis parameter of films assuming a pseudo-cubic cell for the oxynitride compound) (on bulk, $c / a \approx 1.002[10]$ ). This distortion was associated with 
very high permittivity values, for example $\kappa \sim 2000$ (@10kHz, room temperature $(\mathrm{RT})$ ) for the $290 \mathrm{~nm}$ thick film.

The present article falls within the scope of the dielectric properties of oxynitride perovskite compounds since this is still an open debate whether or not these compounds have unusual properties. Our aim is to provide experimental data and compare them to the current models. The present work is based upon our experience on the reactive sputtering deposition of $\mathrm{LaTiO}_{2} \mathrm{~N}[15,16]$ and $\left(\mathrm{Sr}_{1-\mathrm{x}} \mathrm{La}_{\mathrm{x}}\right)_{2}\left(\mathrm{Ta}_{1-\mathrm{x}} \mathrm{Ti}_{\mathrm{x}}\right)_{2} \mathrm{O}_{2} \mathrm{~N}[17,18]$ oxynitride films. Here, our objective is to deposit $\mathrm{SrTaO}_{2} \mathrm{~N}$ films and study the influence of their crystallographic strain on their permittivity. First part of the article is devoted to the optimization of the reactive sputtering deposition of $\mathrm{SrTaO}_{2} \mathrm{~N}$ films by varying the substrate temperature; the second part presents the dielectric characterization at low frequencies of films of different thicknesses and so, different crystallographic strains.

\section{Materials and methods}

$\mathrm{SrTaO}_{2} \mathrm{~N}$ films were synthesized by $\mathrm{rf}$ magnetron sputtering at high temperature using a reactive $\mathrm{Ar}+\mathrm{N}_{2}$ plasma gas. A $2 \mathrm{~mm}$ thick sputtering target was formed by cold pressing $\mathrm{Sr}_{2} \mathrm{Ta}_{2} \mathrm{O}_{7}$ oxide powder, under $80 \mathrm{MPa}$, into a $75 \mathrm{~mm}$-diameter disk. The powder material for the target has been synthesized by solid state route. Stoichiometric amounts of $\mathrm{SrCO}_{3}$ and $\mathrm{Ta}_{2} \mathrm{O}_{5}$ were mixed in isopropanol in an agate mortar for $30 \mathrm{~min}$ and dried at $80^{\circ} \mathrm{C}$ for $1 \mathrm{~h}$. The sample was then pelletized, calcined at $1000^{\circ} \mathrm{C}$ for $15 \mathrm{~h}$, finely ground and further calcined at $1400^{\circ} \mathrm{C}$ for $15 \mathrm{~h}$. The powdered product was clearly identified as $\mathrm{Sr}_{2} \mathrm{Ta}_{2} \mathrm{O}_{7}$ (orthorhombic, S.G. $=$ Cmcm $\left(n^{\circ} 63\right)$ with $a=3.947 \AA, b=27.193 \AA$ and $\left.c=5.690 \AA\right)$ by X-ray diffraction 
(XRD) in agreement with the JCPDS \#70-0248 datasheet (see diffractogramm in Supplementary Data 1).

The oxide target, located $5 \mathrm{~cm}$ from the substrate, was sputtered with an input power of $2.05 \mathrm{~W} . \mathrm{cm}^{-2}(90 \mathrm{~W})$. The chamber was pumped down to a base pressure of $10^{-5} \mathrm{~Pa}$; during depositions, the dynamic pressure was maintained at 5.35 Pa. Depositions were performed at substrate temperatures $\left(\mathrm{T}_{\mathrm{S}}\right)$ ranging from 600 to $900^{\circ} \mathrm{C}$, and the plasma nitrogen content $\left(\mathrm{N}_{2}\right.$ plasma vol.\%) was set at $7.7 \%$, the optimal condition leading to a stoichiometric oxynitride material, as determined in a previous study [17]. Deposition time was fixed at $135 \mathrm{~min}$ for the first series of films and adjusted to the required thickness for the second. Films were deposited on two types of single-crystal substrates obtained from Crystal GmbH (Berlin, Germany): $\mathrm{MgO}(001)$ and conductive niobium-doped (1.4at\%) $\mathrm{SrTiO}_{3}(001)\left(\mathrm{Nb}-\mathrm{SrTiO}_{3}\right)$. The latter has been used as substrate and bottom electrode for the dielectric characterization. Both $\mathrm{MgO}$ and $\mathrm{SrTiO}_{3}$ substrates have a small crystallographic mismatch with the $\mathrm{SrTaO}_{2} \mathrm{~N}$ perovskite (respectively, -4.07 and $+3.44 \%$ ), promoting a textured or epitaxial growth of films.

X-ray diffraction patterns were obtained using a Seifert 3003 PTS diffractometer $(\mathrm{Cu}$ $\mathrm{K}_{\alpha 1}$ radiation). Conventional $\theta-2 \theta$ patterns were recorded at $0.01^{\circ}$ intervals with a $2 \mathrm{~s}$ count time at each step. In order to quantify the thin film orientation, the Lotgering factor $\left(\mathrm{F}_{\mathrm{L}}\right)$ was used. This factor compares the orientation of a thin film versus a randomly oriented material (i.e. powder) and is able to vary from 0 for a non-oriented layer to 1 for a fully oriented layer. The Lotgering factor is calculated using the following relations, considering a (001) orientation of films [19]:

$$
F_{L}=\frac{P_{00 l}-P_{0(00 l)}}{1-P_{0(00 l)}} \quad \text { with } P_{(00 l)}=\frac{\sum I_{(00 l)}}{\sum I_{(h k l)}}
$$

where (hkl) are used for all families of planes, I(00l) and I(hkl) are the intensities of the (00l) and (hkl) indexed peaks, respectively, and the subscript 0 is relative to the powder 
reference diffractogram (JCPDS data). $\varphi$-scan measurements were also done at a tilt angle $\chi=$ $45^{\circ}$, corresponding to the pseudo-cubic (110) plane of the oxynitride compound, in order to evaluate a possible epitaxial growth of films.

Additional X-rays diffraction analysis was performed using a Smart-Lab Rigaku diffractometer in an in-plane $\theta-\theta$ configuration, available on this apparatus by the existence of a fifth axis of rotation of the goniometer that enables to rotate the detector in a plane parallel to the surface sample [20]. The use of a highly parallel linear X-ray beam after a CBO (Cross Beam Optics) mirror [21] and the possibility of adjusting a parallel slit collimator [20] allows to vary the horizontal divergence of the incident beam from $0.1^{\circ}$ to $1^{\circ}$ (angle $\alpha$, with a critical angle of full reflection $\alpha_{c} \approx 0.2^{\circ}$ ). This permits to reach different penetration depth in the sample and so, explore only the first layers of films. The in-plane $a$-axis parameter of each layer is calculated and, if a variation exists, it demonstrates the occurrence of a strain gradient in the sample. Here, $\theta-2 \theta$ patterns were recorded at $0.032^{\circ}$ intervals with a speed of $0.5^{\circ} / \mathrm{min}$, with $\alpha$ varying from 0.4 to $1.0^{\circ}$.

The surface and cross-section morphologies of films were characterized by Scanning Electronic Microscopy (SEM) using a Jeol JSM 5440 SEM with a tungsten filament operating at $10 \mathrm{kV}$. The resolution of the SEM images is close to $5 \mathrm{~nm}$. For thick films, typically thicker than $400 \mathrm{~nm}$, the cross-section observation is easily done and the error on the thickness value is estimated as being $\pm 10 \mathrm{~nm}$. Lower thicknesses were determined from the deposition rate.

UV-visible transmittance spectra were recorded using a Perkin-Elmer Lambda 20 spectrometer in the $200-1100 \mathrm{~nm}$ wavelengths range. For each sample, the absorption coefficient $\alpha$ is calculated from the transmittance $(T)$ using the relation $\alpha=(1 / t)(\ln (1 / T))$, where $t$ is the thickness of the film. The band gap of the material $\left(\mathrm{E}_{\mathrm{g}}\right)$ is calculated assuming a direct allowed transition and using the relation $(\alpha h v)^{2}=h v-E_{\mathrm{g}}$, where $h v$ is the photon energy. In the plot of $(\alpha h v)^{2}$ as a function of $h v$, extrapolation of the linear region of the plot 
at zero gives the value of $E_{\mathrm{g}}$ [22]. The error in the value of $\mathrm{E}_{\mathrm{g}}$ thus determined is estimated to be close to $0.05 \mathrm{eV}$.

Low frequency dielectric properties were measured by a LCR meter (LCR-819 GWInstek). Measurements were made on capacitance structures in which the bottom electrode is constituted by the conducting substrate $\left(\mathrm{Nb}: \mathrm{SrTiO}_{3}\right)$, whereas $200 \mathrm{~nm}$ sputtered silver serves as the top electrode. Measurements were done at $10 \mathrm{kHz}$ and room temperature; external DC voltages $(0-30 \mathrm{kV})$ were applied to point out a possible variation of the permittivity (i.e. tunability).

\section{Results and discussion}

\subsection{Deposition of films}

3.1.2. Optimization as a function of the substrate temperature

Table 1 in Supplementary Data 2 presents the characteristics of the series of films deposited on $\mathrm{MgO}$ (001) substrates by reactive sputtering for the optimization study. The films are named relatively to their substrate temperature, varying from 600 to $900^{\circ} \mathrm{C}$ by step of $50^{\circ} \mathrm{C}$.

Figure 1 presents the deposition rate of films as a function of the substrate temperature. One can observe a gradual decrease of the deposition rate, except for the film deposited at $\mathrm{T}_{\mathrm{S}}=600^{\circ} \mathrm{C}$ which has an unexpected low value. The drop in the deposition rate is explained by the increasing back-sputtering of arriving species on the growing layer as temperature of the substrate increases. Sputtered species find on the heated substrate additional energy to form bonds resulting in a better crystallization of the coating as explicated later, but it also leads to desorption of atoms from the surface, thereby reducing deposition rates. 
The orange coloration of the oxynitride samples is due to the substitution of nitrogen for oxygen in the crystal structure of the films. In the case of the $\operatorname{Sr}_{2} \mathrm{Ta}_{2} \mathrm{O}_{7}$ oxide $\left(\mathrm{E}_{\mathrm{g}}=4.55\right.$ $\mathrm{eV}$ [23]), the valence band is predominantly composed of $2 p(\mathrm{O})$ states. For the oxynitride compound, the $2 p(\mathrm{O})$ and $2 p(\mathrm{~N})$ bands partially overlap, with the $2 p(\mathrm{~N})$ levels, hereafter composing the top of the valence band, higher in energy than the $2 p(\mathrm{O})$ because of the difference of electronegativity between oxygen and nitrogen $\left(\chi_{N}<\chi_{0}\right)$ [11]. Since the $5 d(\mathrm{Ta})$ levels, forming the conduction band, remain basically unchanged, this leads ultimately to a lower band-gap of the oxynitride compound compared to the parent oxide. Figure 1 presents the evolution of the band-gap of films depending on the substrate temperature (an example of a transmittance spectrum as well as the curves for the determination of $E_{g}$ are given in Supplementary Data 3). A continuous decrease is observed, from $E_{g}=2.75 \mathrm{eV}$ for the film deposited at $\mathrm{T}_{\mathrm{S}}=600^{\circ} \mathrm{C}$ to $\mathrm{E}_{\mathrm{g}}=2.40 \mathrm{eV}$ for the film deposited at $\mathrm{T}_{\mathrm{S}}=900^{\circ} \mathrm{C}$, thus approaching the reported value of Oka et al. $(2.27 \mathrm{eV})$ on $\mathrm{SrTaO}_{2} \mathrm{~N}$ films deposited by laser ablation [9] and the value obtained on $\mathrm{SrTaO}_{2} \mathrm{~N}$ bulk material, $\mathrm{E}_{\mathrm{g}}=2.10 \mathrm{eV}$ [23].

$\theta-2 \theta$ X-ray diffraction patterns of the films on $\operatorname{MgO}(001)$ substrates, presented in Figure 2, confirm that the deposited layers are crystallized and we identify them as $\mathrm{SrTaO}_{2} \mathrm{~N}$, with no impurity phase. We have indexed the different diffracted peaks according to a pseudo-cubic cell of $\mathrm{SrTaO}_{2} \mathrm{~N}$, currently used for perovskite materials considering $c \sim \sqrt{ } 2 . a$. We note that indexed intense peaks correspond to the (001) family of planes, indicating a preferred orientation of the layers along the $c$ axis of the oxynitride compound. Moreover, epitaxy of the $\mathrm{SrTaO}_{2} \mathrm{~N}$ films has been checked by recording $\varphi$-scans at a tilt angle $\chi=45^{\circ}$ associated to the (110) plane of the pseudo-cubic cell. The example of the ST- $900^{\circ} \mathrm{C}$ sample is given in Supplementary Data 4; it shows four peaks spaced by $90^{\circ}$ and aligned with the substrate, thus demonstrating the cube on cube growth of the oxynitride on the $\mathrm{MgO}$ substrate, i.e. its epitaxy. This has been verified for all samples. Nevertheless, peaks that do not belong to the (001) family are also seen in Figure 2 (except for the film deposited at the 
highest substrate temperature $\mathrm{T}_{\mathrm{S}}=900^{\circ} \mathrm{C}$ ). They are associated with a limited polycrystalline growth; the films of this series can thus be finally considered as textured films.

Figure 3 present different quantitative crystalline characteristics of films as function of substrate temperature. Figure 3a shows high Lotgering factor $\left(\mathrm{F}_{\mathrm{L}}\right)$ values which confirms the (001) orientation of films; $F_{L}$ stays more or less constant, above 0.9. The rocking-curve $(\Delta \theta)$ (Figure $3 b$ ), calculated as the full width at half maximum of the $\theta$-scan performed on the oriented (004) peak, and $\Delta \phi$ (Figure 3c), full width at half maximum of the $\phi$-scan performed on the (110) plane at a tilt angle $\chi=45^{\circ}$, both decrease with increased substrate temperature. This evolution indicates that the disorientations of the out-of-plane $c$ axis and of the (110) plane of films reduce as $\mathrm{T}_{\mathrm{S}}$ increases. For these highly oriented films, the higher the substrate temperature, the higher the crystallization of films is.

Furthermore, when extracting the crystalline parameters from the $\theta-2 \theta$ diffractogramms obtained at $\chi=0$ ( $c$ parameter) and $45^{\circ}$ ( $a$ parameter), and plotting the crystalline cell volume (V) of the oxynitride films as function of the substrate temperature (Figure 4), one can see a continuous decrease of $\mathrm{V}$ as $\mathrm{T}_{\mathrm{S}}$ increases. The cell volume approaches the bulk value of $\mathrm{SrTaO}_{2} \mathrm{~N}\left(\mathrm{~V}=65.660 \AA^{3}[10]\right)$ and that obtained by Oka et al. on films $\left(65.385 \AA^{3}\right)[9]$.

Surface morphologies of some $\mathrm{SrTaO}_{2} \mathrm{~N}$ films are shown in Figure 5; they seem independent of the substrate temperature. The layers present smooth surfaces with fine granular particles with size below $100 \mathrm{~nm}$. We have observed a sample cracking for $\mathrm{T}_{\mathrm{S}} \geq$ $850^{\circ} \mathrm{C}$ due to the difference between the $\mathrm{MgO}$ (substrate) and $\mathrm{SrTaO}_{2} \mathrm{~N}$ (film) thermal expansion coefficients.

In conclusion, both transmittance and XRD analysis have shown that the characteristics of the films approach those of the $\mathrm{SrTaO}_{2} \mathrm{~N}$ bulk material as the substrate 
temperature increases and so, $\mathrm{T}_{\mathrm{S}}=900^{\circ} \mathrm{C}$ can be considered as the optimal temperature from that point of view. However, since damage can occur on thick samples for $\mathrm{T}_{\mathrm{S}} \geq 850^{\circ} \mathrm{C}$, we have chosen to deposit the following series of films for the dielectric study according to two experimental conditions: the thicker films $(400-900 \mathrm{~nm})$ were deposited at $\mathrm{T}_{\mathrm{S}}=800^{\circ} \mathrm{C}$ and the thinnest films $(30-160 \mathrm{~nm})$ at $\mathrm{T}_{\mathrm{S}}=900^{\circ} \mathrm{C}$.

\subsubsection{Series of films with different thickness}

Table 2 in Supplementary Data 2 presents the characteristics of the series of films for the dielectric study. The $\mathrm{SrTaO}_{2} \mathrm{~N}$ samples were deposited on $\mathrm{Nb}-\mathrm{SrTiO}_{3}(001)$ substrate; they are named according to their thickness $(\mathrm{t}=30,160,400,700$ and $900 \mathrm{~nm})$. The band-gaps of films are in the range $2.20-2.50 \mathrm{eV}$, in good agreement with the values measured in the previous series.

XRD analysis has revealed different crystallization-types among the samples, from epitaxial to polycrystalline depending on the thickness of samples (see $\theta-2 \theta$ diffractograms in Supplementary Data 5). In order to evaluate a potential tetragonal distortion for thinnest films, the ratio $c / a$ has been calculated. When drawing its evolution as a function of the thickness (Figure 6), a clear tendency is observed: the cla ratio has a bimodal distribution. Above 160 $\mathrm{nm}$, the ratio is close to the bulk value $(c / a=1.002[10])$ which indicates the formation of relaxed films. Below, the increase in the ratio is due to the tetragonal distortion of the oxynitride layer imposed by the substrate. The thinnest films are (moderately) strained on the $\mathrm{Nb}-\mathrm{SrTiO}_{3}$ substrate, with $c / a$ values of 1.0075 for ST-30nm and 1.0069 for ST-160 nm. In fact, these films are epitaxially grown, with a clear split of the out-of-plane $c$ and in-plane $a$ parameters, as can be seen in Figure 6. In this series, the splitting is seen only for these thin and epitaxial films. The other films, textured or polycrystalline with higher thickness, present $c$ and $a$ similar values leading to $c / a$ ratios close to bulk. 
Figure 7 presents the additional XRD analysis, by means of a Rigaku diffractometer in an in-plane configuration, performed on a $30 \mathrm{~nm}$ thin film deposited on $\mathrm{MgO}(001)$ substrate in the same run than the $\mathrm{ST}-30 \mathrm{~nm}$ sample (deposited on $\mathrm{Nb}-\mathrm{SrTiO}_{3}$ substrate). First, as expected in the case of a cube on cube growth, the film has a preferred $a$-axis in-plane orientation, with the occurrence of intense (h00) diffracted peaks (Figure 7a). Secondly, the intensity of thin films related peaks falls with increasing $\alpha$ (for example for the (200) peak, Figure $7 \mathrm{~b}$ ). This reflects that the X-ray beam goes more deeply in the structure as $\alpha$ increases and, as a consequence, the thin film contribution decreases to the benefit of the substrate. Third, and most importantly, the angular positions of the (h00) peaks do not shift significantly upon varying $\alpha$; this significates that the in-plane $d$-spacings are constant at different depth in samples. The extracted in-plane axis parameter is $a=4.016 \AA$ (bulk, $a=4.0306 \AA$ ), while the out-of-plane axis is $c=4.076 \AA$ (bulk, $c=4.039 \AA$ ). This denotes a (slight) in-plane compressive strain and a high tensile out-of-plane strain for this sample deposited on $\mathrm{MgO}$. The in-plane XRD analysis showing no variation of the $a$ parameter, one can say that the observed strain is achieved from the first deposited atomic layer. Considering the mismatch $\approx$ - $4.07 \%$ between the $\mathrm{MgO}$ substrate and the $\mathrm{SrTaO}_{2} \mathrm{~N}$ compound, this strain is surely accompanied by immediate formation of misfit dislocations at the interface substrate/film, which may influence the dielectric response of the sample.

\subsection{Dielectric characterization of films}

The evolution of the permittivity ( $\kappa)$ and loss tangent $(\tan \delta)(@ 10 \mathrm{kHz}, \mathrm{RT})$ of films of the second series according to their thickness is presented in Figure 8a. Permittivity varies from 66.5 to 90 whereas the loss tangent ranges from 0.032 to 0.107 . A slight correlation can be proposed between the permittivity and the thickness: the permittivity increases with film thickness, while the losses remain quasi constant. 
When drawing the evolution of the permittivity as function of the crystalline $c / a$ ratio, (Figure 8b), no significant behavior is identified; the highest ratios do no lead to the highest permittivities, and vice-versa. The thinnest film (ST-30nm), with a moderate $c / a=1.0075$, has a quite low permittivity $(\kappa=66.5)$; this could be due to a substrate/film interface with higher defects than bulk film. The ST-400nm has a $c / a$ ratio characteristic of a relaxed film $(c / a=$ 1.0010) and its permittivity $\kappa=73$. These features are not in accordance with the results of Oka et al. obtained on $\mathrm{SrTaO}_{2} \mathrm{~N}$ films grown using Nitrogen Plasma-Assisted Pulsed Laser Deposition (NPA-PLD) [9]. In that case, an extremely high ratio $c / a=1.026$ was reported for a $20 \mathrm{~nm}$-thick film (the permittivity value was not given), while the $290 \mathrm{~nm}$-thick film with a high ratio $(c / a=1.013)$ presents a very high permittivity value $(\kappa \sim 2000)$. In the present study, the attained crystallographic strain may be too low to induce a trans-type $\mathrm{N}$ ordering in the oxynitride structure, as assumed by Oka et al., and so, to impact the dielectric properties. In fact, the moderate $c / a$ ratios of our films deposited on $\mathrm{Nb}-\mathrm{SrTiO}_{3}$ are caused by high values of the in-plane $a$ parameter, as seen in Figure 6. The discrepancy between the two studies could result from the use of different deposition processes (RF reactive sputtering vs. NPAPLD).

Our permittivity values are approaching the one $(\kappa \sim 200$ (@10kHz,RT)) obtained by Kim et al. on oxynitride $\mathrm{BaTaO}_{2} \mathrm{~N}$ film deposited by laser ablation [24]. Our experimental results can also be reconciled with the value $\kappa \sim 350$ (@ 10kHz, RT) achieved by Sun et al. on a $\mathrm{NH}_{3}$ post-annealed $\mathrm{SrTaO}_{2} \mathrm{~N}$ ceramic [8]. The spread between values could come from grain size effects. Indeed, various grains structuring (depending on the thin film deposition process or on the sintering condition) lead to different grain-boundary dead layers thickness and density that affect the permittivity values [25]. Ultimately, our permittivities could be typical of conventional insulating materials, perhaps reflecting the proper dielectric behavior of perovskite oxynitride compounds. 
Finally, the evolution, as a function of the frequency, of the permittivity and losses of one sample (ST-400nm) is presented in Figure 9a: the characteristics are stable in frequency, required condition for integration in telecommunicating devices. Furthermore, no variation of the permittivity when applying a DC electric field has been observed for any sample (for example, for the ST-400nm film in Figure 9b). This significates that films of this series do not present a tunability of their permittivity. The oxynitride films presented here are dielectrics but not ferroelectrics, and their permittivity cannot be used to shift, for example, the resonance frequency of a planar antenna, as in the case of BST films [26]. 


\section{Conclusion}

Perovskite oxynitride $\mathrm{SrTaO}_{2} \mathrm{~N}$ thin films have been deposited by rf reactive magnetron sputtering from an oxide $\mathrm{Sr}_{2} \mathrm{Ta}_{2} \mathrm{O}_{7}$ powdered target. The use of $7.7 \%$ vol. of dinitrogen in the plasma allowed to deposit oxynitride films; their characteristics (band-gap, crystallization) have been shown to approach the ones of the bulk material as the substrate temperature increases up to $900^{\circ} \mathrm{C}$. A dielectric study has been performed on films with thickness ranging from 30 to $900 \mathrm{~nm}$. A slight increase of the permittivity, from 66.5 to 90 , has been observed as thickness increases. The evolution of permittivity as a function of the frequency up to $100 \mathrm{kHz}$ is stable and no tunability as a function of a DC electric field has been evidenced. Diffraction analysis has pointed out a splitting of cell parameters in the case of thin and epitaxial films, while the polycrystalline and textured films and/or thick films have been shown to be relaxed. No relation between crystallographic strain and permittivity has been evidenced, maybe due to the moderate levels of strain attained in the present study. 


\section{Acknowledgements}

The authors gratefully acknowledge Dr. A. Shalimov, Dr. T. Ulyanenkova from Rigaku, and

F. Sennequier from Elexience-France for the X-Ray Diffraction measurements on the RigakuSmartLab equipment. They also acknowledge M. Chevaucherie for technical assistance. 


\section{References}

[1] S.W. Kim, H.I. Choi, M.H. Lee, J.S. Park, D.J. Kim, D.Do, M.H. Kim, T.K. Song, W.J. Kim, Electrical properties and phases of $\mathrm{BaTiO}_{3}-\mathrm{SrTiO}_{3}$ solid solution, Ceram. Int. 39 (2013) S487-S490.

[2] F. Tessier, R. Marchand, Ternary and higher order rare-earth nitride materials: synthesis and characterization of ionic-covalent oxynitride powders, J. Solid State Chem. 171 (2003) 143-151.

[3] M. Jansen, H. P. Letschert, Inorganic yellow-red pigments without toxic metals, Nature 404 (2000) 980-982.

[4] R. Aguiar, D. Logvinovich, A. Weidenkaff, A. Rachel, A. Reller, S.G. Ebbinghaus, The vast colour spectrum of ternary metal oxynitride pigments, Dyes and Pigments 76 (2008) 7075 .

[5] K. Maeda, (Oxy)nitrides with d0-electronic configuration as photocatalysts and photoanodes that operate under a wide range of visible light for overall water splitting, Phys. Chem. Chem. Phys. 15 (2013) 10537-10548.

[6] Y. I. Kim, P.M. Woodward, K.Z. Baba-Kishi, C.W. Tai, Characterization of the structural, optical, and dielectric properties of oxynitride perovskites $\mathrm{AMO}_{2} \mathrm{~N}(\mathrm{~A}=\mathrm{Ba}, \mathrm{Sr}, \mathrm{Ca} ; \mathrm{M}=\mathrm{Ta}$, $\mathrm{Nb}$ ), Chem. Mater. 16 (2004) 1267-1276.

[7] S. G. Ebbinghaus, H.-P. Abicht, R. Dronskowski, T. Muller, A. Reller, A. Weidenkaff, Perovskite-related oxynitrides - Recent developments in synthesis, characterization, and investigations of physical properties, Prog. Solid State Chem. 37 (2009) 173-205.

[8] S-K. Sun, Y-R. Zhang, Y. Masubuchi, T. Motohashi, S. Kikkawa, Additive sintering, post-annealing and dielectric properties of $\mathrm{SrTaO}_{2} \mathrm{~N}$, J. Am. Ceram. Soc. 97 (2014) 10231027.

[9] D. Oka,Y. Hirose, H. Kamisaka, T. Fukumura, K. Sasa, S. Ishii, H. Matsuzaki, Y. Sato, Y. Ikuhara, T. Hasegawa, Possible ferroelectricity in perovskite oxynitride $\mathrm{SrTaO}_{2} \mathrm{~N}$ epitaxial thin films, Sci. Rep. 4 (2014) 4987.

[10] S. Kikkawa, S. Sun, Y. Masubuchi, Y. Nagamine, T. Shibahara, Ferroelectric response induced in cis-type anion ordered $\mathrm{SrTaO}_{2} \mathrm{~N}$ oxynitride perovskite, Chem. Mater. 28 (2016) $1312-1317$. 
[11] C.M. Fang, G.A. de Wijs, E. Orhan, G. de With, R.A. de Groot, H.T. Hintzen, R. Marchand, Local structure and electronic properties of $\mathrm{BaTaO}_{2} \mathrm{~N}$ with perovskite-type structure, J. Phys. Chem. Solids 64 (2003) 281-286.

[12] K. Page, M. W. Stoltzfus, Y.-Il Kim, T. Proffen, P. M. Woodward, A. K. Cheetham, R. Seshadri, Local atomic ordering in $\mathrm{BaTaO}_{2} \mathrm{~N}$ studied by neutron pair Distribution function analysis and density functional theory, Chem. Mater. 19 (2007) 4037-4042.

[13] M. Yang, J. Oro'-Sole', J. A. Rodgers, A. Belen Jorge, A. Fuertes, J. P. Attfield, Anion order in perovskite oxynitrides, Nature Chem. 3 (2011) 47-52.

[14] Y. Hinuma, H. Moriwake, Y. Zhang, T. Motohashi, S. Kikkawa, I. Tanaka, First principles study on relaxor-type ferroelectric behavior without chemical inhomogeneity in $\mathrm{BaTaO}_{2} \mathrm{~N}$ and $\mathrm{SrTaO}_{2} \mathrm{~N}$, Chem. Mater. 24 (2012) 4343-4349.

[15] C. Le Paven-Thivet, L. Le Gendre, J. Le Castrec, F. Cheviré, F. Tessier, J. Pinel, Oxynitride perovskite $\mathrm{LaTiO}_{\mathrm{x}} \mathrm{N}_{\mathrm{y}}$ thin films deposited by reactive sputtering, Progr. Solid State Chem. 35 (2007) 299-308.

[16] Y. Lu, C. Le Paven, H. T. Nguyen, R. Benzerga, L. Le Gendre, S. Rioual, F. Tessier, F. Cheviré, A. Sharaiha, C.Delaveaud, X. Castel, Reactive sputtering deposition of perovskite oxide and oxynitride lanthanum titanium films: structural and dielectric characterization, Crystal Growth and Design 13 (2013) 4852-4858.

[17] C. Le Paven, L. Le Gendre, R. Benzerga, F. Cheviré, F. Tessier, S. Jacq, S. TraoréMantion, A. Sharaiha, Growth of (Sr,La)-(Ta,Ti)-O-N perovskite oxide and oxynitride films by radio frequency magnetron sputtering: Influence of the reactive atmosphere on the film structure, J. Cryst. Growth 413 (2015) 5-11.

[18] S. Jacq, C. Le Paven, L. Le Gendre, R. Benzerga, F. Cheviré, F. Tessier, A. Sharaiha, Deposition and dielectric characterization of strontium and tantalum-based oxide and oxynitride perovskite thin films, Solid State Sci. 54 (2015) 22-29.

[19] F.K. Lotgering, Topotactical reactions with ferromagnetic oxides having hexagonal crystal structures, J. Inorg. Nucl. Chem 9 (1959) 113-123.

[20] http://www.rigaku.com/fr/products/xrd/smartlab; http://www.rigaku.com/newsletters/mabu/pdf/TF4_In-Plane.pdf

[21] http://www.rigaku.com/downloads/journal/RJ26-2/RJ26-2_29-30.pdf 
[22] D. Kubelka, L. Munk, Ein beitrag zur optik der farbanstriche, Z. Tech. Phys. 12 (1931) 593-601.

[23] Y. Mizuno, H. Wagata, K. Yubuta, N. Zettsu, S. Oishi, K. Teshima, Flux growth of $\mathrm{Sr}_{2} \mathrm{Ta}_{2} \mathrm{O}_{7}$ crystals and subsequent nitridation to form $\mathrm{SrTaO}_{2} \mathrm{~N}$ crystals, Cryst. Eng. Comm. 15 (2013) 8133-8138.

[24] Y. I. Kim, W. Si, P. M. Woodward, E. Sutter, S. Park, T. Vogt, Epitaxial thin-film deposition and dielectric properties of the perovskite oxynitride $\mathrm{BaTaO}_{2} \mathrm{~N}$, Chem. Mater. 19 (2007) 618-623.

[25] J. Petzelt, S. Kamba, J. Hlinka, Ferroelectric soft modes in ceramics and films, in New developments in advanced functional ceramics. Ed. L. Mitoseriu, Indian Series of Appl. Phys., Transworld Research Network 37/661, Trivandrum,.Kerala, India, pp. 387-421 (2007).

[26] H-V. Nguyen, R. Benzerga, C. Borderon, C. Delaveaud, A. Sharaiha, R. Renoud, C. Le Paven, S. Pavy, K. Nadaud, H. W. Gundel, Miniaturized and reconfigurable notch antenna based on a BSTferroelectric thinfilm, Mater. Res. Bull. 67 (2015) 255-260. 


\section{Figure Captions}

Figure 1. Evolution as function of the substrate temperature $\left(T_{S}\right)$ of the deposition rate and of the band gap $\left(\mathrm{E}_{\mathrm{g}}\right)$ of $\mathrm{SrTaO}_{2} \mathrm{~N}$ films deposited on $\mathrm{MgO}$ substrate by reactive sputtering.

Figure 2. $\theta-2 \theta$ diffractogramms of $\mathrm{SrTaO}_{2} \mathrm{~N}$ films deposited on $\mathrm{MgO}(001)$ substrate by reactive sputtering at various substrate temperatures. Indexation is made according to a pseudo-cubic cell of $\mathrm{SrTaO}_{2} \mathrm{~N}$.

Figure 3. Evolution as function of the substrate temperature $\left(\mathrm{T}_{\mathrm{S}}\right)$ of: (a) the Lotgering factor $\left(\mathrm{F}_{\mathrm{L}}\right)$, (b) $\Delta \theta$ recorded on the (002) peak and (c) $\Delta \varphi$ recorded on the (110) plane at $\chi=45^{\circ}$ of $\mathrm{SrTaO}_{2} \mathrm{~N}$ films deposited on $\mathrm{MgO}(001)$ substrate by reactive sputtering (a pseudo-cubic cell is assumed for $\mathrm{SrTaO}_{2} \mathrm{~N}$ ).

Figure 4. Evolution of the volume of the crystalline cell (considering a pseudo-cubic cell) as function of substrate temperature $\left(\mathrm{T}_{\mathrm{S}}\right)$ of $\mathrm{SrTaO}_{2} \mathrm{~N}$ films deposited on $\mathrm{MgO}(001)$ substrate by reactive sputtering. The value of the cell volume for bulk $\mathrm{SrTaO}_{2} \mathrm{~N}$ [10] is drawn by a dotted line.

Figure 5. Surface morphologies observed by $\mathrm{SEM}$ of $\mathrm{SrTaO}_{2} \mathrm{~N}$ films deposited on $\mathrm{MgO}(001)$ substrate by reactive sputtering at different substrate temperatures.

Figure 6. Evolution as function of the thickness of $\mathrm{SrTaO}_{2} \mathrm{~N}$ films deposited on $\mathrm{Nb}$ $\mathrm{SrTiO}_{3}(001)$ substrate by reactive sputtering of the $c / a$ ratio, the out-of-plane $c$ and the inplane $a$ parameters. Values reported for bulk are also drawn [10].

Figure 7. In-plane $\theta-2 \theta$ XRD patterns of a $30 \mathrm{~nm} \mathrm{SrTaO}_{2} \mathrm{~N}$ thin film deposited on $\mathrm{MgO}(001)$ substrate (twin film of the ST-30nm sample) recorded at different angle $\alpha$ of the detector: (a) 
full-range diffractogram and (b) detail centered on the (200) film peak. Measurements were done on a SmartLab Rigaku apparatus.

Figure 8. Evolution of the permittivity $(\kappa)$ and the loss tangent $(\tan \delta)$ as function of the thickness of $\mathrm{SrTaO}_{2} \mathrm{~N}$ films deposited on $\mathrm{Nb}-\mathrm{SrTiO}_{3}(001)$ substrate by reactive sputtering (measurement @10kHz,RT).

Figure 9. Evolution of the permittivity ( $\kappa$ ) as function of: (a) the $c / a$ ratio, (b) the cell volume, (c) the out-of-plane $c$ parameter and (d) the in-plane $a$ parameter (measurement @ 10kHz,RT). 


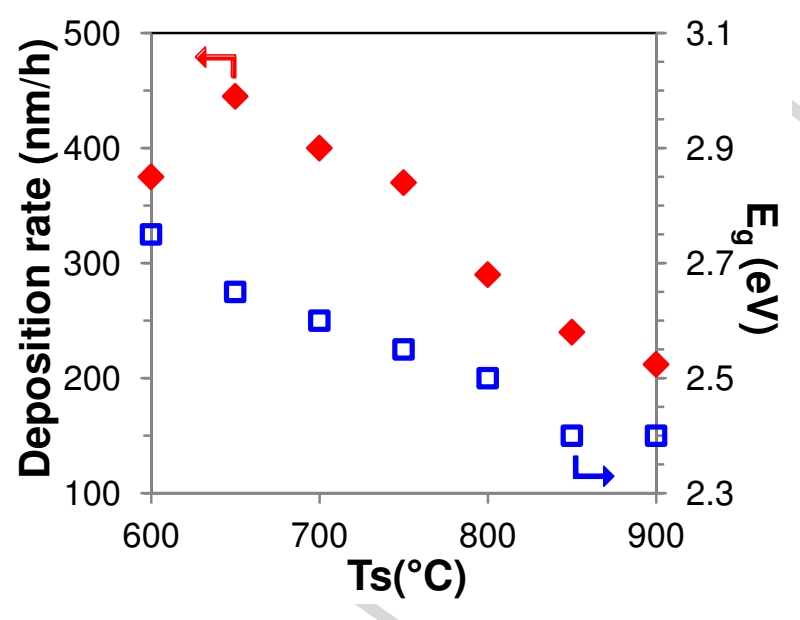

Fig. 1 


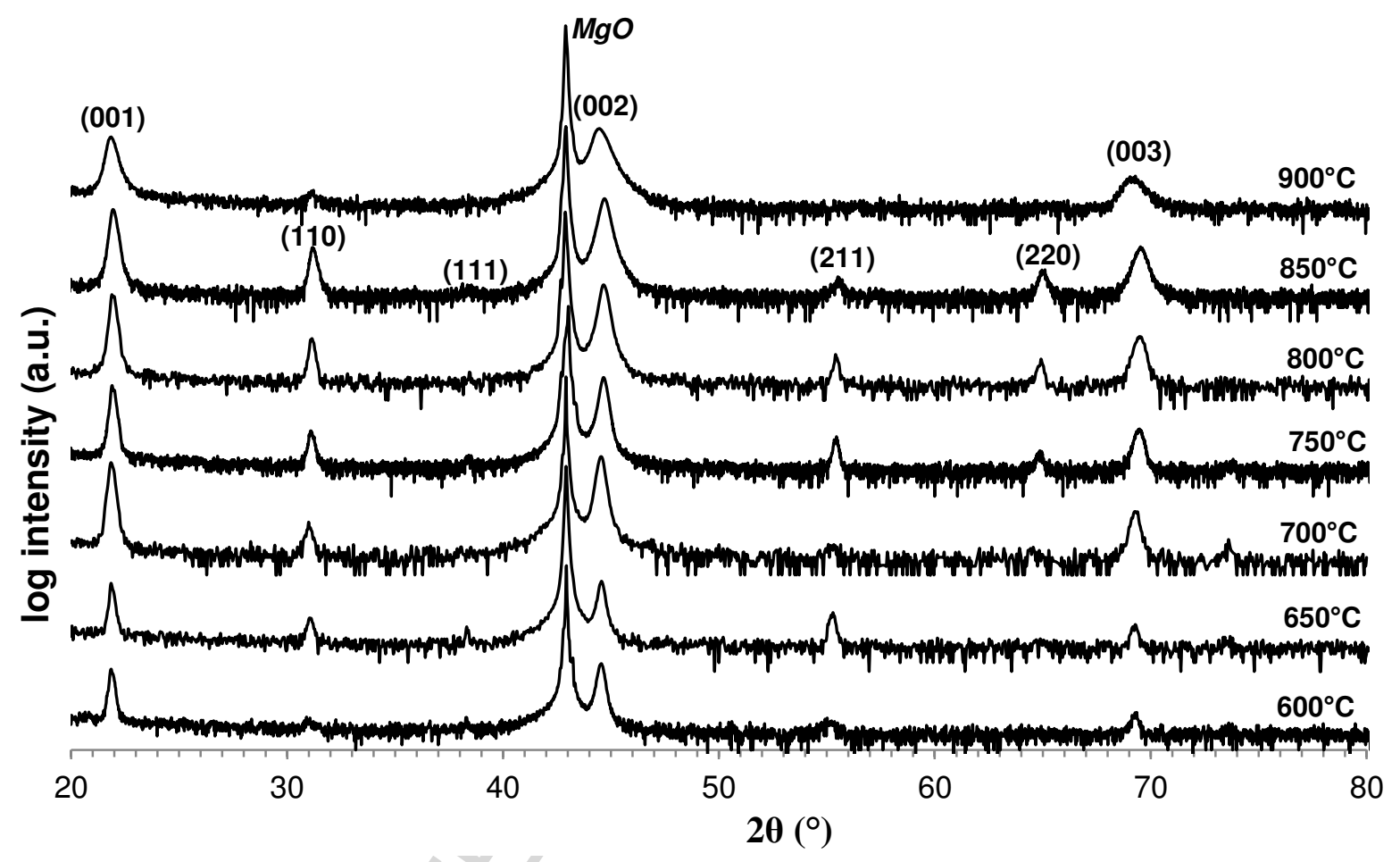

Fig. 2 

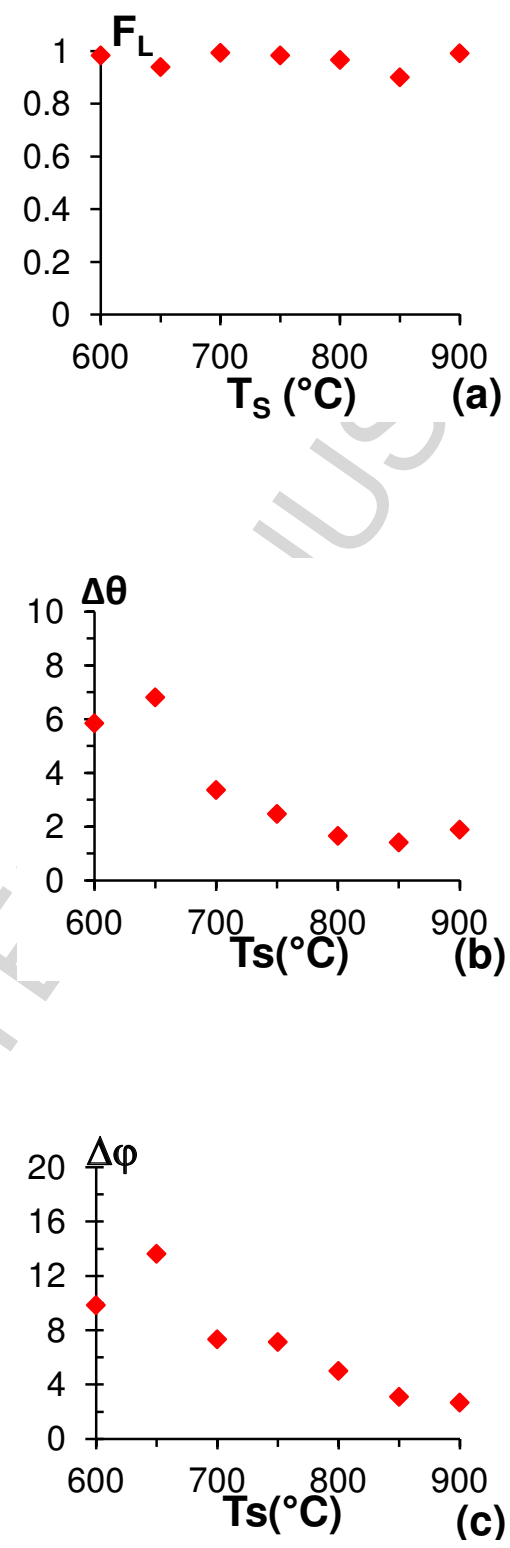

Fig. 3 


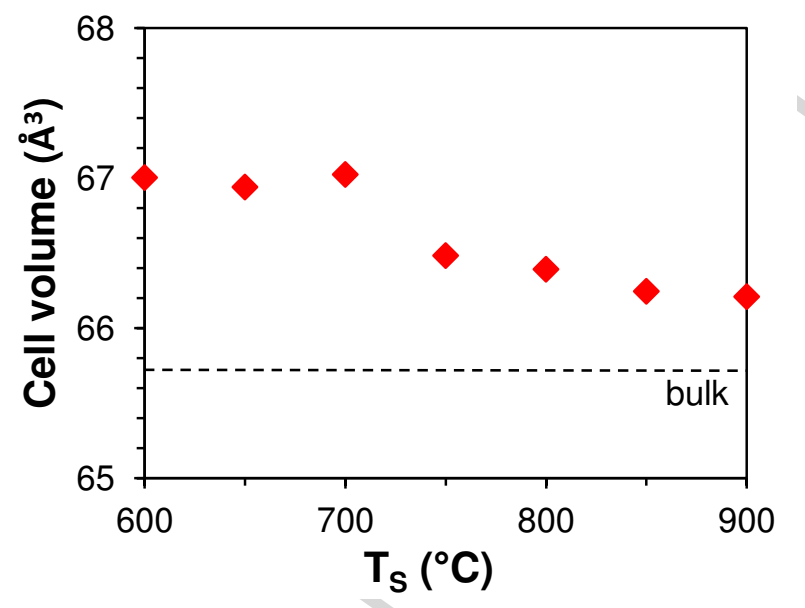

Fig. 4 
Fig. 5

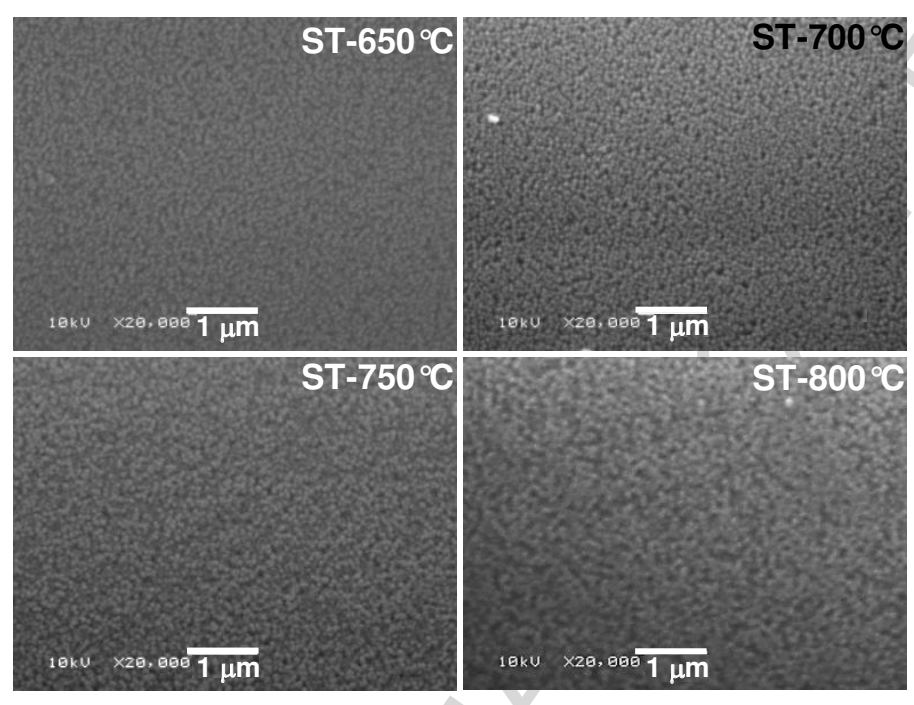




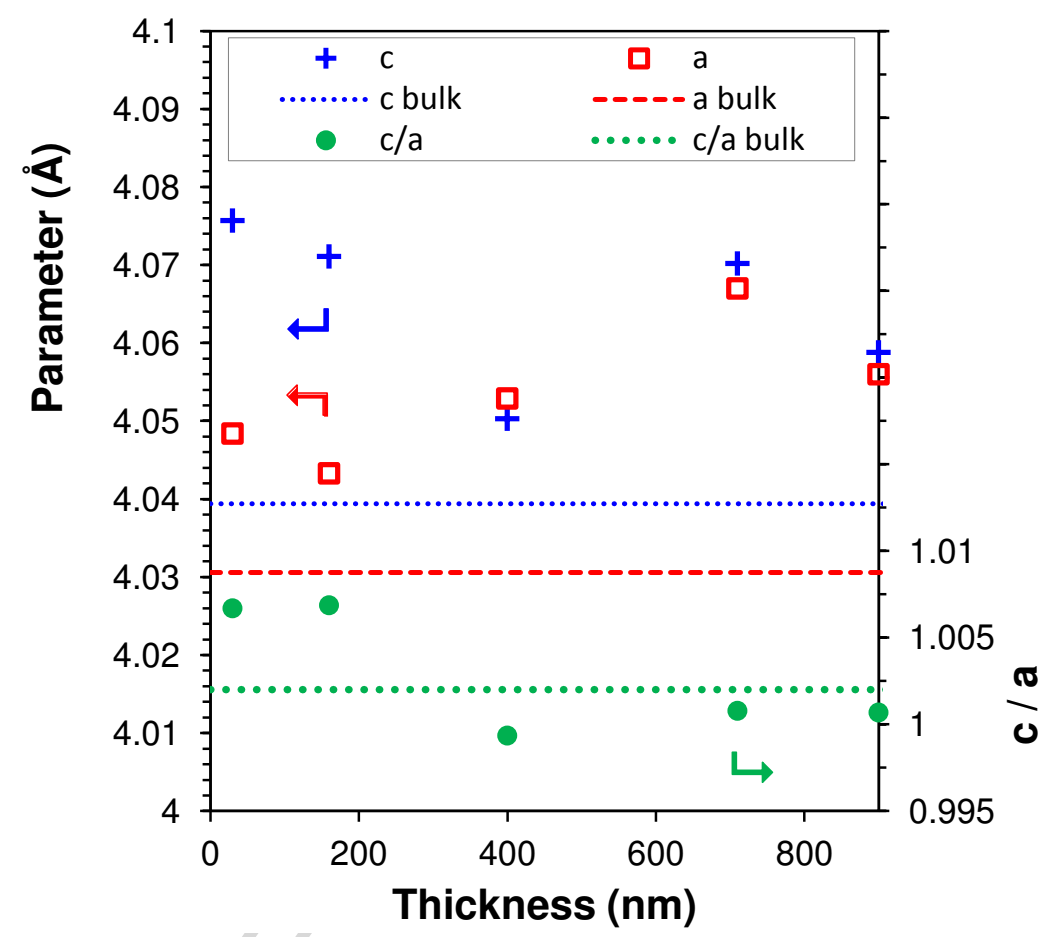

Fig. 6 

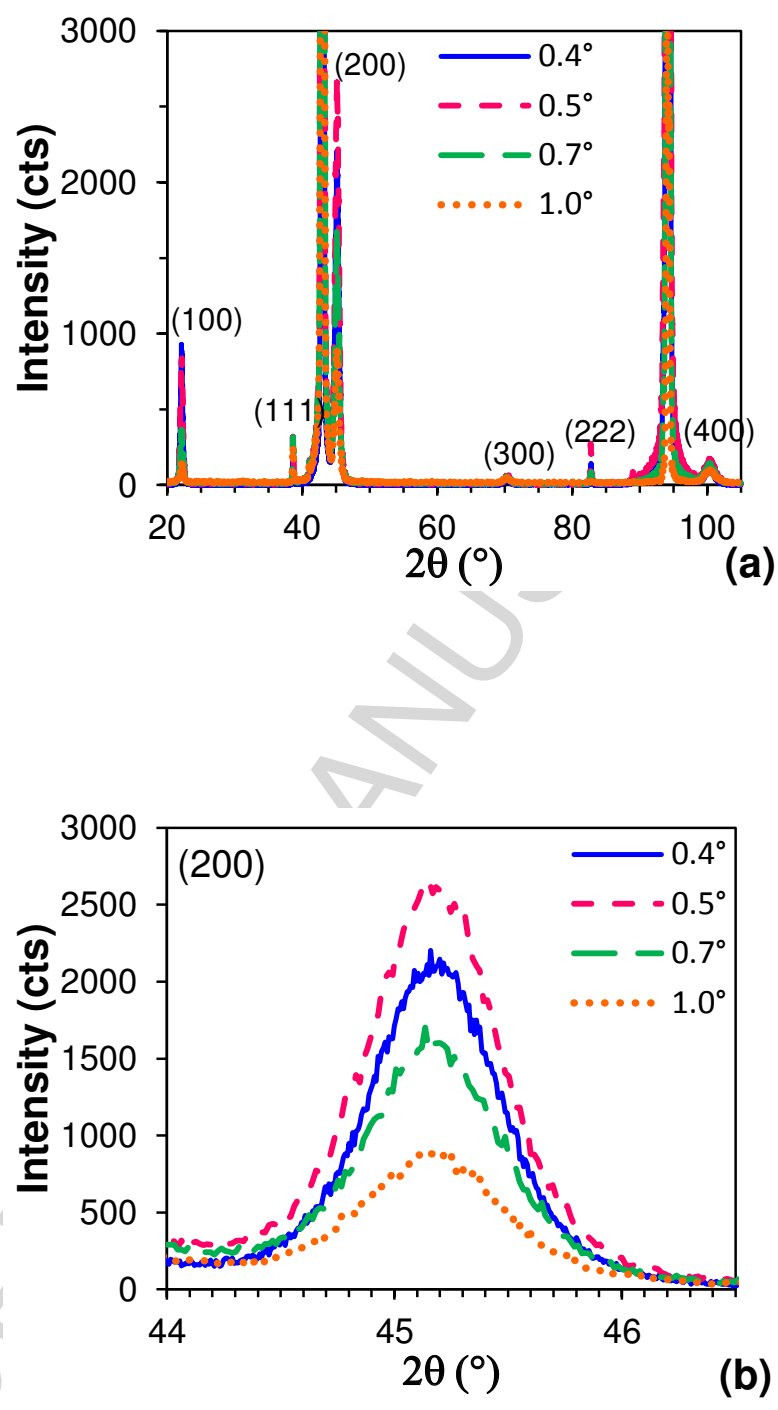

Fig. 7 

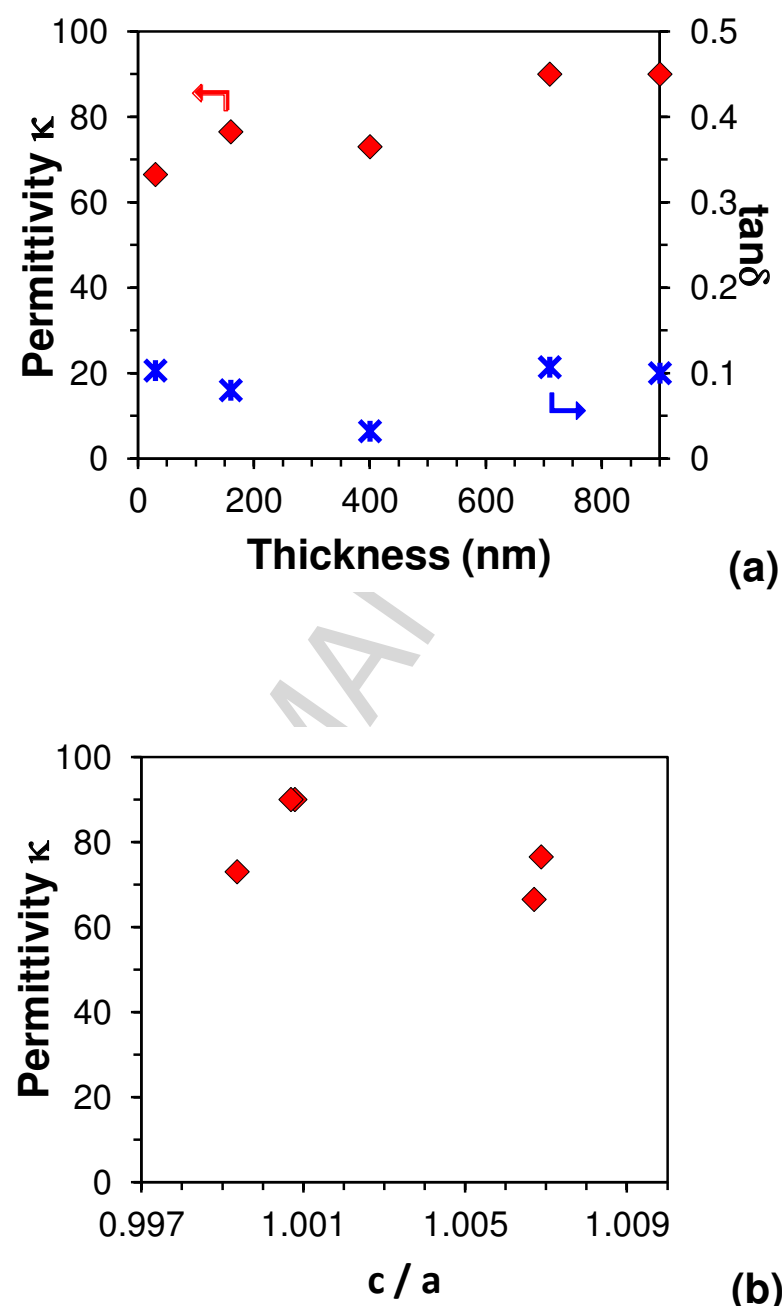

(b)

Fig. 8 

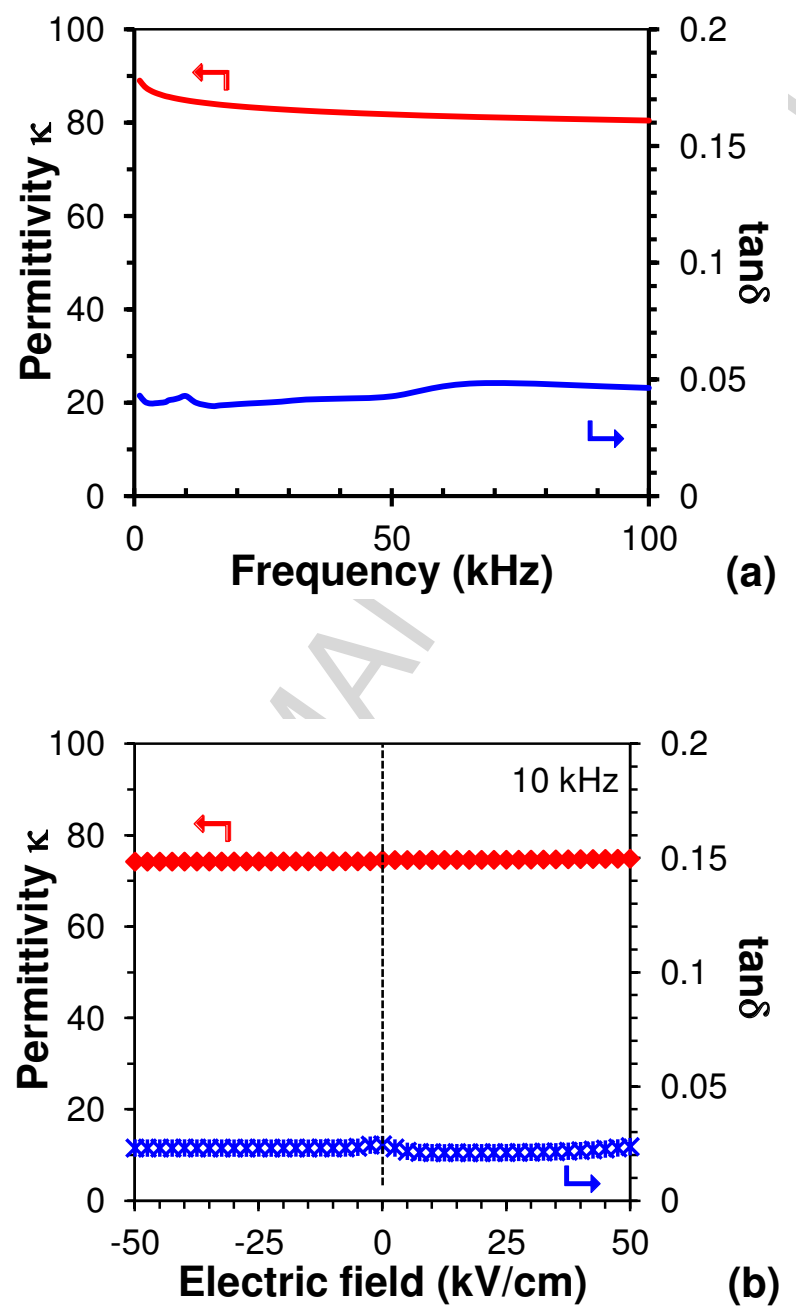

Fig. 9 


\section{Graphical Abstract}

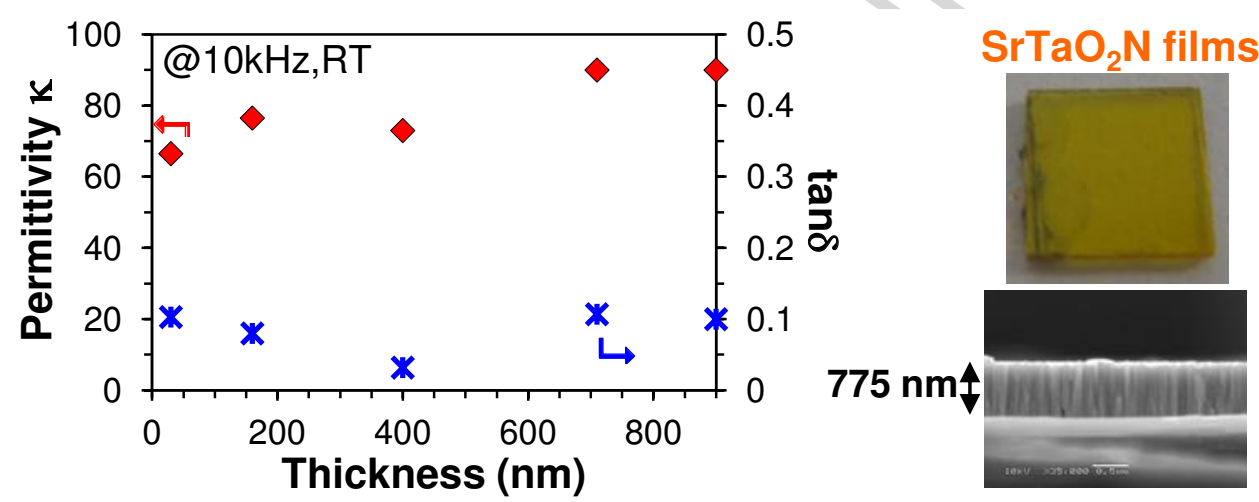

